\title{
Single incision extended video assisted transcervical thymectomy
}

\author{
Marcello Migliore ${ }^{1}$, Alessandra Criscione ${ }^{1}$, Marco Nardini $^{1}$, Francesco Patti $^{2}$, Francesco Borrata $^{1}$ \\ ${ }^{1}$ Thoracic Surgery, Department of General and Medical Specialties, University of Catania, Policlinico University Hospital of Catania, Catania, Italy; \\ ${ }^{2}$ Neurology Department, Policlinico University Hospital of Catania, Catania, Italy \\ Correspondence to: Marcello Migliore, MD, PhD, FETCS. Thoracic Surgery, Policlinico University Hospital of Catania, Via S. Sofia 78, 95124, \\ Catania, Italy. Email: mmiglior@unict.it.
}

\begin{abstract}
In the last 30 years the introduction of VATS in the surgical practice made possible to perform a wide range of thoracic operations including thymectomy. We describe our single incision video-assisted transcervical thymectomy (VATT) for non-thymomatous myasthenia gravis and/or small $(<2 \mathrm{~cm})$ intrathymic thymoma in 13 patients. The mean operation time was of 164 minutes (range, 45-275 minutes). The length of hospitalization was 3 days (range, 2-5 days). Decrease of symptoms was obtained in the entire group after a mean follow up of 79 months (range, 8-150 months), and two patients had a complete stable remission. In conclusion, single incision extended transcervical thymectomy (TT) is a safe and successful procedure which allows a complete excision of the anterior mediastinal fat.
\end{abstract}

Keywords: Uniportal surgery; myasthenia gravis; thymectomy; transcervical; non-thymomatous myasthenia gravis

Received: 18 September 2017; Accepted: 25 September 2017; Published: 28 October 2017.

doi: 10.21037 /jovs.2017.10.06

View this article at: http://dx.doi.org/10.21037/jovs.2017.10.06

\section{Introduction}

It is well known that the first thymectomy has been described in 1912 (1), but only after the famous paper of Blalock et al in 1941, who reported their surgical experience and demonstrated amelioration of symptoms after removal of the thymus gland in patients with MG (2), thymectomy became known worldwide. Since then, several studies demonstrated that thymectomy improves symptoms with patients who needed less medication than those receiving conservative medical treatment alone (3). Historically, the most used approach to perform thymectomy was the trans-sternal approach for the excellent visualization of the anterior mediastinum that allows a complete resection of the mediastinal fat with all ectopic thymic tissue.

In 1988 Cooper described an easier and reproducible technique to perform transcervical thymectomy (TT) (4), and in 1993, the thoracoscopic approach to thymectomy was first reported by Lerut in Leuven (5).

Nevertheless, in the last 20 years the introduction of uniportal VATS in the surgical practice made possible to perform a wide range of thoracic operations including thymectomy including non-intubated thymectomy (6-14).
The introduction of uniportal VATS also for mediastinal diseases and the recent availability of dedicated instruments (15-17) made possible nowadays to perform also thymectomy (18-20).

In 2016, Wolfe et al. published the results of a prospective multicenter randomized trial comparing complete transsternal thymectomy and prednisone versus prednisone alone as primary treatment for myasthenia gravis. The authors demonstrated that the thymectomy was statistically superior in improving symptoms, reducing the need of medical therapy (54 vs. 32 patients; estimated $95 \%$ CI 22) and the number of readmission for exacerbation of myasthenia (37 vs. 9 patients; $\mathrm{P}<0.001$ ) (21).

In this manuscript we describe our technique of video assisted TT for MG, and review our clinical results.

\section{Indications for surgical treatment}

A transcervical approach was offered to all patients who did not respond to medical treatment (9). We performed VATT for Non-thymomatous myasthenia gravis and/or small $(<2 \mathrm{~cm})$ intrathymic thymoma in 13 patients. 


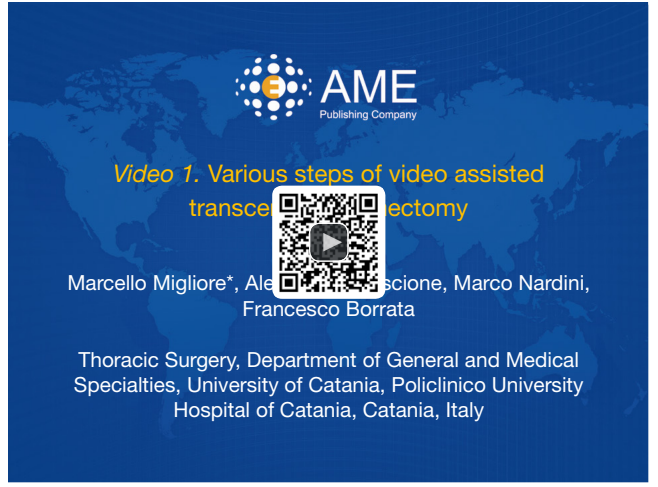

Figure 1 Various steps of video assisted transcervical thymectomy (23). Available online: http://www.asvide.com/articles/1768

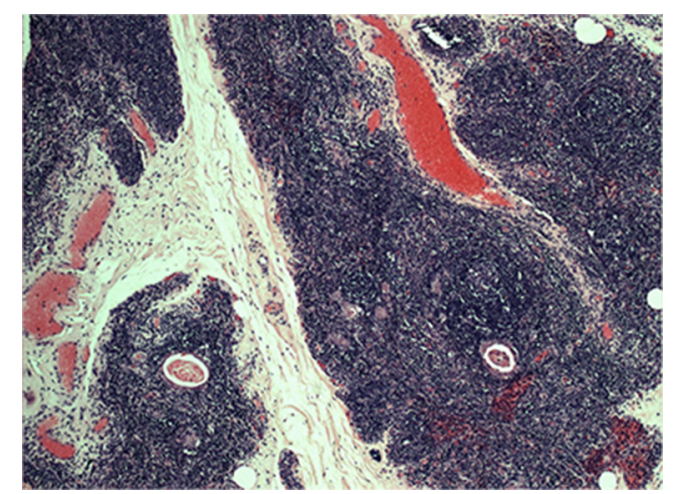

Figure 2 Histology shows Hassall's corpuscles (H\&E stain, $\mathrm{LM} \times 26$ ).

\section{Surgical technique}

The following surgical technique has been previously described by our group (10). The patient is positioned supine and the neck is hyperextended. Intubation is performed using a single or double lumen-tube (22). A 4-6 cm collar skin incision is performed 2-cm above the sternal notch, the infrahyoid muscles are spread along their raphae. The thyroid gland is retracted cranially, and the upper poles of the thymus are visualized, and the superior mediastinum is entered. Then, the surgeon moves to the head of the patient and the two monitors are positioned according to the surgeon's preference.

A sternal retractor is used to suspend the sternum. A 0 or 30 degree 5 -mm optic can be used. Dissection is performed anteriorly and laterally to the gland (Figure 1). When the dissection is performed posteriorly, the left brachiocephalic vein is identified. To expose the Keynes veins, the thymus is moved anteriorly. Although we were used to apply vascular clips, we recently utilize the high energy device to coagulate and cut thymic veins and arteries.

The gland is separated by blunt and sharp dissection from the pericardium and pleurae. After the gland is removed, the optic permits to perform a "true" extended thymectomy, and the anterior mediastinum is cleared from the fat down to the diaphragm (Figure 1).

In 5 patients $(39 \%)$ we felt intraoperatively that the thymectomy was incomplete and therefore we performed an additional $2 \mathrm{~cm}$ left uniportal VATS to make the excision of the mediastinal fat more radical. We perform a periareolar incision in man (Figure 2) and in the submammary fold in woman. Through this access, in one patient we also performed the resection of a left pulmonary nodule. The sternotomy was always ready if necessary.

\section{Results}

Video assisted transcervical technique was used in 13 patients ( 8 women, 5 males, mean age 43 years) affected by non thymomatous generalized MG.

Preoperative stage, according to MGFA classification, was stage I in 2 patients (15.4\%), II in 4 (30.8\%), III in 3 $(23 \%)$ and stage IV in 1 patient $(7.7 \%)$. The mean operation time was of 164 minutes (range, 45-275 minutes) with minimal blood loss. One patient had a myasthenic crisis after surgery, resolved with intravenous immunoglobulins. The length of hospitalization was 3 days (range, 2-5 days). Final histology demonstrated thymic hyperplasia in 8 cases (61.5\%), Hassall's corpuscles in 2 cases (15.4\%) (Figure 3), adipose involution in 1 case $(7.7 \%)$ and a $\mathrm{B} 2$ thymoma in 1 case $(7.7 \%)$. The pulmonary nodule demonstrated as normal lung tissue.

Decrease of symptoms was obtained in the entire group after a mean follow up of 79 months (8-150 months), and two patients had a complete stable remission.

\section{Discussion}

Several VATS techniques have been described (5-14,18-20) acknowledging the esthetic advantages over mid-line sternotomy. Although TT is a true minimally invasive technique (24-28), the most known and strong criticisms regarding TT are the "incomplete" clearance of the mediastinal fat compared to an open surgery, and the difficult teaching because the surgical field is narrow.

Our experience confirms that the use of the optic during TT improves visualization of the operating field and 


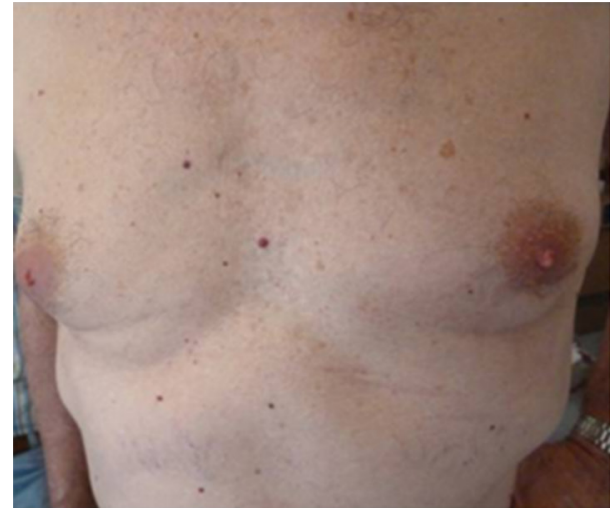

Figure 3 A 1.5-cm additional periareolar access.

eliminates the reported disadvantages. Firstly, because the anterior/superior mediastinal space $(6,10-12)$ including the aortopulmonary window are well displayed on the monitor, the mediastinal fat can be removed extensively. Secondly, because everyone in the operating room can follow the various steps of the operation, the VATT is simpler to learn.

In our experience because we felt intraoperatively that thymectomy was incomplete in $39 \%$ of patients, we performed an additional $2 \mathrm{~cm}$ left uniportal VATS to make the excision more radical, but this decision is surgeon's dependent and could certainly influence long term surgical results.

To note, the fact that several studies demonstrated that clinical results are extremely similar after thymectomy performed via transcervical approach or after traditional VATS (24-28), confirms that VATT is an excellent option to treat MG. Moreover, one advantage of VATT over classic VATS techniques is the absence of chest pain usually caused by the insertion of intercostal ports.

In conclusion, single incision extended TT is a safe and successful procedure which permits a complete excision of the anterior mediastinal fat.

\section{Tips and tricks}

* Single incision VATT is a safe approach for non thymomatous myasthenia gravis;

* Our experience confirms the advantages versus the classical TT overcoming the risk of "lesser" thymectomy;

* A small $2 \mathrm{~cm}$ thymoma could be easily and safely removed;

* In case of a suspicious incomplete resection it is very easy to perform a second incision on the left chest to ensure radicality.

\section{Acknowledgements}

None.

\section{Footnote}

Conflicts of Interest: The authors have no conflicts of interest to declare.

Informed Consent: Written informed consent was obtained from the patient for publication of this manuscript and any accompanying images.

\section{References}

1. Schumacher R, Roth J. Thymektomie Bei cenem fall von morbus basedowii mit myasthenie. Med Chir 1912;25:746.

2. Blalock A, McGehee HA, Ford FR, et al. The treatment of myasthenia gravis by removal of the thymus gland. JAMA 1941;117:1529-33.

3. Keynes G. Surgery of the thymus gland. Lancet 1954;1:1197-208.

4. Cooper JD, Al-Jilaihawa AN, Pearson FG, et al. An improved technique to facilitate transcervical thymectomy for myasthenia gravis. Ann Thorac Surg 1988;45:242-7.

5. Coosemans W, Lerut TE, Van Raemdonck DE. Thoracoscopic surgery: the Belgian experience. Ann Thorac Surg 1993;56:721-30.

6. de Perrot M, Bril V, McRae K, et al. Impact of minimally invasive trans-cervical thymectomy on outcome in 
patients with myasthenia gravis. Eur J Cardiothorac Surg 2003;24:677-83.

7. Rea F, Bortolotti L, Girardi R, et al. Thoracoscopic thymectomy with the "da Vinci" surgical system in patient with myasthenia gravis. Interact CardioVasc Thorac Surg 2003;2:70-2.

8. Hsu CP, Chuang CY, Hsu NY, et al. Subxiphoid approach for video-assisted thoracoscopic extended thymectomy in treating myasthenia gravis. Interact CardioVasc Thorac Surg 2002;1:4-8.

9. Migliore M, Vecchio I, Rampello L, et al. Multisciplinary approach of non-thymomatous myasthenia gravis. Acta Med Medit 2012;28:211-3.

10. Migliore M, Alongi G, Rampello L, et al. Video assisted trans-cervical thymectomy: a minimally invasive approach to treat non-thymomatous myasthenia gravis. Ann Ital Chir 2013;84:667-70.

11. Bramis J, Diamantis T, Tsigris C, et al. Video-assisted transcervical thymectomy. Surg Endosc Interv Tech 2014;18:1535-8.

12. Shigemura N, Shiono H, Inoue $M$, et al. Inclusion of the transcervical approach in video-assisted thoracoscopic extended thymectomy (VATET) for myasthenia gravis: a prospective trial. Surg Endosc Interv Tech 2006;20:1614-8.

13. Jiang L, Liu J, Shao W, et al. Non-intubated subxiphoid uniportal video-assisted thoracoscopic thymectomy using glasses-free 3D vision. J Thorac Dis 2016;8:E1602-4.

14. Yablonsky P, Pischik V, Tovbina MG, et al. The results of video-assisted thoracoscopic thymectomies in Saint Petersburg, Russia: 20-year of experience. J Vis Surg 2017;3:113.

15. Migliore M, Deodato G. A single-trocar technique for minimally invasive surgery of the chest. Surg endosc 2001;15:899-901.

16. Migliore M. Efficacy and safety of single-trocar technique for minimally invasive surgery of the chest in the treatment of noncomplex pleural disease. J Thorac CardioVasc Surg 2003;126:1618-23.

doi: 10.21037 /jovs.2017.10.06

Cite this article as: Migliore $M$, Criscione A, Nardini M, Patti F, Borrata F. Single incision extended video assisted transcervical thymectomy. J Vis Surg 2017;3:154.
17. Migliore M, Calvo D, Criscione A, et al. Uniportal video assisted thoracic surgery: summary of experience, minireview and perspectives. J Thorac Dis 2015;7:E378-80.

18. Scarci M, Pardolesi A, Solli P. Uniportal video-assisted thoracic surgery thymectomy. Ann Cardiothorac Surg 2015;4:567-70.

19. Ooi A, Sibayan M. Uniportal video assisted thoracoscopic surgery thymectomy (right approach). J Vis Surg 2016;2:13.

20. Wu CF, Gonzalez-Rivas D. Uniportal video-assisted thoracoscopic thymectomy. Video-Assist Thorac Surg 2017;2:25.

21. Wolfe GI, Kaminski HJ, Aban IB, et al. Randomized Trial of Thymectomy in Myasthenia Gravis. N Engl J Med 2016;375:511-22.

22. Grasso N, Celestre C, Borrata F, et al. An unexpected difficult intubation in a patient with myasthenia gravis undergoing video-assisted transcervical thymectomy. BMJ Case Rep 2013;2013:bcr2013010135.

23. Migliore M, Criscione A, Nardini M, et al. Various steps of video assisted transcervical thymectomy. Asvide 2017;4:452. Available online: http://www.asvide.com/articles/1768

24. DeFilippi VJ, Richman DP, Ferguson MK. Transcervical thymectomy for myasthenia gravis. Ann Thorac Surg 1994;57:194-7.

25. Zielinski M, Kuzdzal J, Szlubowski A, et al. Transcervicalsubxifoid-videothoracoscopic "maximal" thymectomy operative technique and early results. Ann Thorac Surg 2004;78:404-10.

26. Shrager JB, Deeb ME, Mick R, et al. Transcervical thymectomy for myasthenia gravis achieves results comparable to thymectomy by sternotomy. Ann Thorac Surg 2002;74:320-7.

27. Bril V, Kojic J, Ilse WK, et al. Long-term clinical outcome after transcervical thymectomy for myasthenia gravis. Ann Thorac Surg 1998;65:1520-2.

28. Masaoka A, Yamakawa Y, Niwa H, et al. Extended thymectomy for myasthenia gravis patients: a 20-year review. Ann Thorac Surg 1996;62:853-9. 